\title{
"Help me to take care": Professional expectations about using an application in heart failure
}

\author{
Virna Ribeiro Feitosa Cestari*1, Lorena C. de Souza ${ }^{1}$, Raquel S. Florêncio ${ }^{1}$, Maria G.V. Sobral ${ }^{1}$, Vera L.M.P. Pessoa ${ }^{1}$, \\ Thiago S. Garces ${ }^{1}$, George Jó Bezerra Sousa ${ }^{1}$, Maria Lúcia Duarte Pereira ${ }^{1}$, Lara L.V. Damasceno ${ }^{2}$, Francisca Diana \\ da Silva Negreiros ${ }^{3}$, Thereza M.M. Moreira ${ }^{1}$ \\ ${ }^{1}$ Clinical Care in Nursing and Health, State University of Ceará, Fortaleza, Brazil \\ ${ }^{2}$ Nurse Department, State University of Ceará, Fortaleza, Brazil \\ ${ }^{3}$ Universidade Federal do Ceará Hospital Universitário Walter Cantídio, Fortaleza, Brazil
}

Received: October 10, 2021

Accepted: November 17, $2021 \quad$ Online Published: November 24, 2021

DOI: $10.5430 /$ jnep.v12n4p21

URL: https://doi.org/10.5430/jnep.v12n4p21

\begin{abstract}
Objective: To understand the expectations of the professionals about the construction and use of an educational and follow-up application to care.

Methods: Phenomenological and qualitative study. Convenience and purposive sampling were carried out and in-depth individual interviews with 35 professionals from the multidisciplinary team, between September and October 2020 in Brazil. All interviews were audio-recorded and data analyzed using the hermeneutic circle. The COREQ checklist was employed to report on the current study.

Results: Two main units of meaning emerged: (a) The care of the person who lives with heart failure; and (b) The care of the person with heart failure intermediated by an application. Care for the person with the disease brings together elements related to the identification of demands and understanding of their surroundings, with guidance and use of technologies.

Conclusions: The professionals were favorable to the development of an application and considered it beneficial. The use of it, would allow the approximation between patients and their family and the multidisciplinary team; respect the patient's needs and overcome the precariousness of the health system.
\end{abstract}

Key Words: Cardiovascular, Heart failure, Mobile applications, Patient-centred care

\section{INTRODUCTION}

Heart failure (HF) is a chronic multifactorial syndrome, associated with several comorbidities and varied presentation of symptoms, which converge for a worse prognosis. Patients with HF struggle to follow self-care plans, essential for improving the quality of life. ${ }^{[1]}$ Disease management interventions with patient training, education, and clinical follow-up should be integrated into the care system, as they reduce hospitalization and increase survival. ${ }^{[2]}$ In response, multiple technological strategies have been developed by health professionals, such as mobile applications, and their benefits are notorious. ${ }^{[3,4]}$

It is necessary to give a voice to the professionals of the multidisciplinary team, because, through the lived experience being a professional who cares, there will be countless contributions. ${ }^{[5]}$ Each professional has something to say about the phenomenon of illness due to HF; listening to them attentively offers the opportunity to bring the technology of the world closer to the experience of the caregiver, in which obstacles and challenges to ethical and efficient care for people

\footnotetext{
*Correspondence: Virna Ribeiro Feitosa Cestari; Email: virna.ribeiro@ hotmail.com; Address: Avenue Doctor Silas Munguba, 1700-Itaperi, Fortaleza, Ceará, Brazil.
}

Published by Sciedu Press 
with HF present themselves. Thus, care is an aspect inherent to the human condition and, regardless of the vehicle that promotes this action, the act of caring is relational.

Care emerges from different perspectives. Heidegger, ${ }^{[6]}$ shows the human being's relationship with the world and expresses care as an act that occupies an ontological sense, proper to human nature. ${ }^{[7]}$ Now, care is based on the essence of being and is consolidated with the construction of bonds. Thus, thinking about the patient with HF is to understand the being and his relationship with others, ${ }^{[8]}$ so that they can develop a human and supportive practice, in addition to the technique: the zealous look at the other with respect and appreciation of the human condition.

An application developed based on structured knowledge and a systematic process, oriented to the needs of users is the foundation of the practice; ${ }^{[9]}$ widens the possibility of taking care of what is not yet taken care of; it favors critical attitudes and allows to evaluate and transform actions in authentic care. Nevertheless, there is a shortage on the subject, as the research carried out excludes professionals from the process of building the application. ${ }^{[10,11]}$ In this perspective, the phenomenological method is relevant to investigate the expectations of health professionals to develop designs and resources useful for an application for care.

This study aimed to understand the expectations of the professionals of the multidisciplinary team of patients with HF for the development and use of an educational and follow-up application to provide care.

\section{MethodS}

\subsection{Design}

This phenomenological study employed a qualitative research approach with data collection via face-to-face individual interviews.

\subsection{Scenario and participants}

The study was carried out in a tertiary health institution in the Northeast region of Brazil, a reference in the diagnosis and treatment of heart and lung diseases. The choice for the institution is justified by the complex care provided to people with HF, consisting of an outpatient unit (Transplantation and Heart Failure Unit - UTIC), an Inpatient Unit, and a Cardiac Rehabilitation Unit, with the active performance of a trained multidisciplinary team.

The multidisciplinary team of the units that take care of patients with HF is made up of 57 professionals (five doctors, 12 nurses, 23 nursing technicians, three nutritionists, five physiotherapists, two psychologists, two social workers, three dentists, and an occupational therapist). For intention- ality, professionals who met the following inclusion criteria were invited: belonging to the active staff, performing daily consultations/orientations to the person with $\mathrm{HF}$, and having experience of caring for patients with $\mathrm{HF} \geq 1$ year. Professionals away from the service were not part of the research.

Forty professionals met the inclusion criteria. There were no refusals to participate, however, a doctor and a social worker did not participate because they were on vacation, which made their participation in the research unfeasible. After identification and selection, 38 professionals were previously contacted by message, via Whatsapp, according to the number informed by the unit coordinator, to participate in the study. Each interview was scheduled according to the professional's availability and held in a private and reserved area at the work institution itself, to ensure privacy and minimize discomfort.

Data collection was preceded by the pilot study to test and adapt the interview script with three professionals. Once adequate, the three previously sensitized professionals were excluded. Finally, 35 professionals participated in the study.

\subsection{Data collection}

For data collection, individual, semi-structured interviews were conducted by two researchers Ph.D. students, with experience in qualitative research and cardiology. The interviewers explained the purpose of the study and, during the interview, occasionally reminded the participants that the study aimed at developing a health application, which guaranteed relevant content and without deviation from the scope. A smartphone with a voice recorder application was used for the interviews.

The interviews were conducted in a dialogical and empathic perspective, which favored the expression of relevant and guiding aspects for pre-understanding; had a minimum duration of 12 minutes and a maximum duration of 43 minutes, with an average duration of 22.3 minutes, based on guiding questions and their derivations (see Table 1), developed based on literature reviews and researchers' interests. The interviews were fully transcribed by the first author and checked by a second person, to maintain scientific rigor. Transcripts will be archived for five years and recordings have been deleted. Data collection started in September 2020, ending in October of the same year.

\subsection{Data analysis}

For the analysis of the speeches obtained, the hermeneutic circle, proposed by Martin Heidegger, was used in his work Being and Time: ${ }^{[6]}$ previous position, previous vision, and previous conception. The interpretive movement proposed by the philosopher must be understood as an opening in the 
understanding-world, constituted by intertwined moments. In the previous position, the interpretation is characterized by the understanding of everyday see-around. In a later moment, there is the appropriation-of-understanding, in which the interpretation is based on a previous view. Based on the understanding and the seen, the interpretation starts to conceptualize, either provisionally or definitively; then formulates a previous conception (see Figure 1).

Table 1. Question script for the semi-structured interview

\begin{tabular}{|c|c|}
\hline Main questions & Derivations \\
\hline $\begin{array}{l}\text { What information is offered to the } \\
\text { person with Heart Failure and their } \\
\text { family members? }\end{array}$ & $\begin{array}{l}\text { - What are the guidelines that patients with Heart Failure and their families receive during } \\
\text { the consultation? And which ones should be reinforced with each consultation? } \\
\text { - Do you use any educational material to guide your consultation? } \\
\text { - Do you provide any support material for the patient and their family members? }\end{array}$ \\
\hline $\begin{array}{l}\text { How to use an application to care } \\
\text { for a person with Heart Failure? }\end{array}$ & $\begin{array}{l}\text { - What do you think of the idea of condensing this information in a mobile application to } \\
\text { - help care for the person with Heart Failure? } \\
\text { - What features and functionality do you believe the application should contain? } \\
\text { everyone? How should it be presented and delivered to the patient and his companion? } \\
\text { - What do you think would be challenging in using this application? } \\
\text { - Do you believe that this technology can be incorporated into your work routine? }\end{array}$ \\
\hline
\end{tabular}

Six hundred and two codes were extracted from the professionals' speeches, consisting of words, sentences, and paragraphs were condensed into 10 units of meaning. These units were compared based on similarities and differences and sorted into 10 sub-themes which constitute the manifest content by two researchers. Finally, these units underwent two reduction processes until two units of meaning emerged. Any differences of opinion were discussed until a consensus was reached.

The descriptions of the statements are presented using the letter " $\mathrm{P}$ " for professionals, followed by Arabic numerals from 1-35, corresponding to the order of the interviews, and the professional category, to preserve the anonymity of those surveyed. The Consolidated Criteria for Reporting Qualitative Research (COREQ) guide was applied to verify the scientific quality of the research.

\subsection{Research rigor}

This study adopted the quality criteria of Lincoln and Guba: ${ }^{[12]}$ credibility, transferability, reliability, and confirmability. For credibility, the data collection process was detailed and the interpretation and analysis of the data were reviewed by three independent reviewers. The analysis results were sent to two participants to verify the consistency of the described content. For transferability, the descriptors detail the study environment, participants, context, and method. To satisfy confidence, the interpretations were reviewed by a study researcher (specialist and theoretical nurse in the care of patients with HF), who was not involved in the collection or analysis of the data. Still, the researcher searched about the analysis process and the results with two researchers who want experience in qualitative research and Heidegger's phenomenology. To meet the confirmability, the researchers revealed as units of meaning without prejudices and their assumptions.

\subsection{Ethical considerations}

The study was guided by the principles of Resolution of the National Health Council 466/2012, which regulates research involving human beings. The research was carried out after approval by the Research Ethics Committee.

\section{RESUlts}

The 35 participants were from 20 to 67 years old (median 35 ), and $85.7 \%$ were female. Of the total, $34.3 \%$ were nurses. Regarding academic degrees, three had technician level; 11 were postgraduates; seven had residence; four were doctors and one was post-doctor. Experience time in caring for people with HF varied from one to 25 years (median six years) (see Table 2).

The professionals commonly used their mobile phones for phone calls, short message services, internet search, and application use (music, video, social network and delivery, and urban mobility services); $62.8 \%$ of professionals used APP for health and only $8.6 \%$ reported using it for HF: Heart Failure Mobile, Score Magic, Chads2Vasc, Score Seattle, Cardio Papers e the Protocols of the Brazilian Society of Cardiology (SBC).

Analysis evolved elucidation of concepts immanent to the meanings immediately demonstrated. Therefore, two units of sense have emerged by phenomenological reduction: 1) 
the care to the person who co-exists with HF, which involves ways of caring and its fragilities and 2) the care to the person with HF intermediated by an APP, which is on expectations and barriers in implementing its technological tool (see Table 3).

The care to a person who co-exists with HF reunites elements related to integral care, orientations, and use of technologies. It unveils that even though the care is planned and structured according to protocols, it should be singularized and individualized: "Focus is not only caring for the heart; many problems around [the patient] may worsen the situation [...] whether in the social or familiar contexts, knowing what happens with the patient is fundamental" (P9, Psychologist).

Cardiac illness permeates many elements and it is necessary to comprehend them. Living with a person with $\mathrm{HF}$, the care should be beyond the act; by being-with, professionals may involve with the ones they care for: "[...] We must run away from the superficial care of just prescribing medicines, sometimes with unreadable letters and not explained, which confuses patients. [...] What are the doubts [from the patient] What are [the patient's] feelings? How is [the patient] doing? These are simple but clear questions that bond us. We cannot just consult or care by itself” (P8, Nurse).

"I don't say everything in all appointments. I ask how they are if they are following the orientations, what are the questions. From what I hear and understand by the body language, I am giving orientations" (P26, Nurse).
Table 2. General characteristics of the professionals $(n=35)$

\begin{tabular}{|c|c|c|}
\hline Characteristics & $\mathbf{n}^{\dagger}(\%)^{\ddagger}$ & Median \\
\hline Age (years) & & 35.0 \\
\hline Gender, Women & $30(85.7)$ & \\
\hline \multicolumn{3}{|l|}{ Professional category } \\
\hline Nurse & $12(34.3)$ & \\
\hline Physiotherapist & 05 (14.3) & \\
\hline Doctor & $04(11.4)$ & \\
\hline Nutritionist & $03(8.6)$ & \\
\hline Dentist & $03(8.6)$ & \\
\hline Nursing technician & $03(8.6)$ & \\
\hline Psychologist & $02(5.7)$ & \\
\hline Social worker & $02(5.7)$ & \\
\hline Occupational Therapist & $01(2.8)$ & \\
\hline \multicolumn{3}{|l|}{ Academic degree } \\
\hline Technical level & $03(8.6)$ & \\
\hline Specialists & $11(31.4)$ & \\
\hline Residence & $07(20.2)$ & \\
\hline Master & 09 (25.7) & \\
\hline Doctors & $04(11.4)$ & \\
\hline Post-doctor & $01(2.8)$ & \\
\hline \multicolumn{3}{|l|}{ Purpose of mobile phone use $\mathrm{f}^{\S}$} \\
\hline Voice call & $35(100.0)$ & \\
\hline Short message service & $35(100.0)$ & \\
\hline Internet search & $35(100.0)$ & \\
\hline $\begin{array}{l}\text { Application use (music, vídeo, social network } \\
\text { and delivery, and urban mobility services) }\end{array}$ & $35(100.0)$ & \\
\hline Health application & $22(62.8)$ & \\
\hline $\mathrm{HF}^{\natural}$ application & $03(8.6)$ & \\
\hline Time of experience of caring for people with HF & & 6.0 \\
\hline
\end{tabular}

Table 3. Heideggerian hermeneutic circle for the construction of units of meaning

\begin{tabular}{|c|c|c|c|c|}
\hline PREVIOUS & \multicolumn{3}{|l|}{ PREVIOUS VISION } & PREVIOUS \\
\hline 602 extractions & Units of meaning & Reduction 1 & Reduction 2 & Units of sense \\
\hline \multirow{10}{*}{$\begin{array}{l}\text { The professional-being } \\
\text { has expectations } \\
\text { regarding the care to a } \\
\text { person with } \mathrm{HF}^{\dagger} \\
\text { intermediated by an } \\
\text { application }\end{array}$} & $\begin{array}{l}\text { Presential caring orientations } \\
\text { have multidisciplinary character }\end{array}$ & \multirow{2}{*}{$\begin{array}{l}\text { Caring a patient with } \\
\mathrm{HF}^{\dagger} \text { and its strategies }\end{array}$} & \multirow{5}{*}{$\begin{array}{l}\text { Ways of caring for } \\
\text { a patient with } \mathrm{HF}^{\dagger}\end{array}$} & \multirow{7}{*}{$\begin{array}{l}\text { Thee care to the } \\
\text { person who co-exists } \\
\text { with } \mathrm{HF}^{\dagger}\end{array}$} \\
\hline & $\begin{array}{l}\text { Using educative Technologies } \\
\text { in caring environments }\end{array}$ & & & \\
\hline & Integral and individualized care & \multirow{3}{*}{$\begin{array}{l}\text { Ways of caring for a } \\
\text { patient with } \mathrm{HF}^{\dagger}\end{array}$} & & \\
\hline & Planning individual care & & & \\
\hline & Weaknesses of caring & & & \\
\hline & Familiar context & \multirow[b]{2}{*}{ Coexisting with $\mathrm{HF}^{\dagger}$} & \multirow[b]{2}{*}{$\begin{array}{l}\text { Co-existing with } \\
\mathrm{HF}^{\dagger}\end{array}$} & \\
\hline & $\begin{array}{l}\text { Access to rights, goods, and } \\
\text { health services }\end{array}$ & & & \\
\hline & $\begin{array}{l}\text { Barriers and obstacles in } \\
\text { compiling guidelines in an APP }\end{array}$ & \multirow{2}{*}{$\begin{array}{l}\text { Expectations about } \\
\text { complications and } \\
\text { orientations by an } \\
\text { APP }\end{array}$} & \multirow{3}{*}{$\begin{array}{l}\text { Expectations of } \\
\text { caring for a patient } \\
\text { with } \mathrm{HF}^{\dagger} \\
\text { intermediated by an } \\
\text { APP }\end{array}$} & \multirow{3}{*}{$\begin{array}{l}\text { The care to the person } \\
\text { with } \mathrm{HF}^{\dagger} \\
\text { intermediated by an } \\
\text { APP }\end{array}$} \\
\hline & $\begin{array}{l}\text { Benefits of composition and } \\
\text { orientations on an APP }\end{array}$ & & & \\
\hline & $\begin{array}{l}\text { Implementation of an App in the } \\
\mathrm{HF}^{\dagger} \text { clinic }\end{array}$ & $\begin{array}{l}\text { Implementation of an } \\
\text { App in the } \mathrm{HF}^{\dagger} \text { clinic }\end{array}$ & & \\
\hline
\end{tabular}

Note. †: Heart Failure. 
Since that, planning the care must be thoughtful, considering the person's demands, clinical conditions, time diagnosed, previous knowledge about the illness, and the environment, as being-in-the-world: "We perform a clinical evaluation regarding their health situation; only after, it is made the plan of actions to be done" (P1, Dentist).

"Demands are variable: family issues such as marriage or with children; working issues; sexuality [...] The patient with CI with indication to transplant suffers by imagining the transplantation moment, the changes, limitations, and many other possibilities from it" (P9, Psychologist).

"[the disease] generates an immense fragility because we know that there is a cut point by income and social class; it is a population that suffers, many of them are not alphabetized, many are aged; this, often related to abusive use of legal and illegal substances (psychoactive) worsen prognosis. [...] We seek to open the patient's mind to understand that treatment is not only medication but everything that surrounds him/her influences treatment, as social condition" (P29, Social Worker).

In this perspective, caring for a person with HF involves several levels of knowledge. Among those, information related to dealing with the disease in the space of the physical and social space: "[...] I give orientations regarding the severity of the disease, possible causes, importance of medications, diet, water and sodium intake, physical and sexual activity" (P22, Doctor).

"[the patients] are orientated to perform adequate oral hygiene; to use and store toothbrushes; to use, clean, and storage dental prosthesis and tongue cleaning" (P2, Dentist).

"[orientations] regarding hospital discharge, daily activities, [...] the need for keeping exercises, and the importance of cardiac rehabilitation" (P6, Physiotherapist).

"[...] regarding energy conservations and daily activities. [...] how they should dress, how to wear shoes, how to take showers, and on the home organization" (P11, Occupational therapist).

"[...] regarding the social assistance benefits, retirement, and access to the continuous cash benefit program" (P30, Social worker).

"[...] violation of rights, abandonment, and family's lack of responsibility" (P29, Social worker).

In the pursuit of promoting authentic care, strategies to education such as follow up by the multidisciplinary team and use of technologies enhance it. They enhance comprehension about being ill without relieving the person of his responsibility with self-care: "All professionals work together in favor of life. [...] The CI silently progresses and, the more advances, the more complications bring. Because of that, patients need a team that guides them about the illness, each one in its area of knowledge" (P19, Doctor).

"[...] Understand it, we must explain to both patient and caregiver about medications, physical activity, proper diet, self-care, screening, symptoms control, complications, and, in some cases, cardiac transplantation. How can one professional approach all of this? Nobody works alone. [...] There is no caring without the team, patient, and family/caregivers. One depends on the other to achieve success" (P18, Physiotherapist).

"[...] Collective educative actions. I bring materials such as "the aliments traffic lights", salt sachets to the patients associate to aliments that they daily consume, fruits to squeeze, and demonstrate the amount of liquid of each one. They like and assimilate better" (P17, Nutritionist).

"I have elaborated an illustrative material to show the patient how his/her heart works and the types of respiratory support" (P28, Physiotherapist).

"We have a folder, but we give it only in the first consultation. It is simple, but it has useful information [...] it was created by a medication company" (P27, Nurse).

However, it was identified in the discourses that caring presented fragilities, mostly due to the number of patients that need consultations and the number of professionals. Moreover, absence of other professional categories (pharmacists, physical educators, and psychiatrist); absence of public policies and lack of communication among healthcare networks: "The patient returns to me every three or six months because there are many of them. So, it is difficult to have a proper follow up" (P16, Nutritionist).

"There is no psychosocial follow-up (social worker, occupational therapist, psychiatrist, and psychologist). [...] There is no pharmacist to give and talk about medications, there is no physical educator in cardiac rehabilitation. [...] There are many policy limitations, which give no support to patients with CI. There is no clear or current information regarding the rights of these patients. There is no interaction among policies, there is no conversation. Because of that, [the care] is fragile. [...] The treatment is centered on the illness, so we have to overcome these limitations to the patient to be fully assisted" (P29, Social worker).

The absence of educative materials also fragilizes caring because the person and his/her relatives follow a consultation routine in which appointments are made according to his/her clinical condition. When hospitalized, the person is 
supported by health professionals to care; however, hospitals discharge is marked by a feeling of unsafety and fear of complications: "When they are hospitalized, we can control the illness [...] many are accompanied by relatives, which help a lot in caring. In the hospital environment, this control is easier. At home, it is complicated because they cannot control medication intake, diet, water intake. Thus, the disease worsens and they are readmitted" (P32, Nurse technician).

"The patient goes home in a void; they probably get lost [in the treatment]" (P15, Nurse).

"New consultations depend on the clinical condition. If it is a patient recently discharged from outpatient service, his/her new consultations are likely to be more frequent to see the therapeutic response. [the return] can occur within a week of 15 days, even one month. When it is stabilized in functional class II to III, it can be in three months [...] he/she retains only what it is said during the consultation, noting in hands" (P4, Doctor).

Given the discourse, it was seen that an APP represented the possibility of a new direction of caring. A way of caring respecting singularities and surpassing fragilities of health systems: "It is the future. In all areas, it is what is going to happen, mostly in CI because it is a chronic condition with difficult treatment and follow up. This application would help a lot, doubtless" (P7, Doctor).

"[...] Instead of writing much information, the professional can simply show where this information is in the application, which is more practical and more beneficial to the patient. $\mathrm{He} / \mathrm{she}$ can now have a resource that supports his/her decisions" (P17, Nutritionist).

"The application would be very helpful because the information is diverse. When information is presented organized, it enhances comprehension, understanding to all the ones involved in the caring process" (P31, Nurse technician).

"With the application you can surpass the walls of the hospital; it is offering another way of caring" (P32, Nurse technician).

"The patients from the countryside or the ones who live far will be benefited" (P16, Nutritionist). "[the App] would help to strengthen the bond with patient and family" (P8, Nurse).

On the other hand, some barriers were cited by the professionals in using and implementing an APP, such as age range and social factors: "Sometimes, technology is so sophisticated that intimidates the user, mostly the aged ones" (P15, Nurse).

"The most important [barriers] would be accessibility; economic situation, which is very different among patients; digi- tal literacy, because many of them cannot understand how to use; altered cognitive function and functional illiteracy" (P3, Dentist).

"The need for accessing the internet would be an important barrier" (P32, Nurse technician).

Still, regarding the barriers, some professionals questioned the costs of the App: "Economic aspect is a limitation point [...] I think, within SUS, this App should be free" (P2, Dentist). "If there is a cost, few [patients] will buy" (P31, Social worker).

Some cautions must be taken in developing an APP, such as design, functionality, and attractive resources. Professionals highlight the need for an intuitive App, with an inviting and ludic design: "[the APP] could be like a diary, registering all relevant information, guided by the team [multidisciplinary]. [...] It should have a pleasant design, colorful, but without strong colors. [...] with flowcharts or mental maps, to turn information easy and quick" (P13, Nurse).

"Figures and information must be simple, the graphical part must be attractive, big letters" (P4, Doctor).

"The application must be ludic, tab with small games such as crosswords, questions related to the theme. The patient would read a text and after answer questions like crosswords, link columns, association" (P18, Physiotherapist).

In the discourses, the choice for inserting resources that enable comprehension of information was considered relevant to stimulate adhesion and surpass some barriers:

"The voice command would be a form of including patients who do not know writing" (P14, Nurse).

"[a resource of] direct contact with professionals, by texting or calling; even online consultations" (P8, Nurse).

"I believe that using valid visual and auditive resources, by making texts available into audio would be easier for the user." (P30, Social worker).

"It would be very useful for having a system to manage information, like a control panel. This information would go to a database and the professional would have access to the evolution of each patient" (P7, Doctor).

"It can bring an option where the patient could contact emergency. Then, if the patient feels seek, he/she would press a button that directly calls the emergency service" (P22, Doctor).

Professionals expectations were also regarding how the App would be delivered to the patients: "After development, make the professional deliver it [the APP], instead of making it 
available in the download stores" (P7, Doctor).

"[the APP] should be presented by the researcher him/herself. $[\ldots]$ the researcher would present to professionals in a meeting and, after that, with the patients, to show and explain what [patient and professional] would do with it; that it will bring benefits" (P11, Occupational therapist).

"The application could be made available on many platforms, such as computers, tablets, and stores like Google Play, Apple Store, Microsoft Store" (P2, Dentist).

"To indicate an application by social networks would be good because the range is higher. It could reach more people with CI from different health institutions" (P32, Nurse technician).

Generally, professionals were favorable to the development of an APP with educative content and with patient's follow up. They considered it beneficial to caring and enabling the approximation of the patient with the family and multidisciplinary team.

\section{Discussion}

We sought to understand the expectations of health professionals about the use of an educational and follow-up application for people with HF. We tried to make sense of the care actions and promote reflection on the reality that appears in everyday life, to produce relevant information. These can guide the construction of a technological tool that offers care in the way of being-with the other. Still, this understanding is a possibility of approximation, which recognizes that human care goes well beyond technological care.

In the phenomenon that appears between falling ill and appropriating the nuances of the disease, the person with HF must be fully assisted. In this perspective, professionals establish themselves as being-with (Mitsein) in the relationship they establish with the patient, and, from this relationship, care emerges. ${ }^{[8]}$ Care refers to being-with-other co-presences in the world; it is present in every relationship, in every action in the world. ${ }^{[6]}$ As being-in-the-world, the professional who cares, finds the possibility of living authentically and assumes his responsibility, in a movement of concern. The latter consists in helping the other to become transparent and free; it is guided by consideration and expresses the dedication to do something for someone and show themselves as being-with-the-other. ${ }^{[13]}$

The multidisciplinary team in this study understood authentic care for people with HF as the development of an empathic relationship, of real help, overcoming obstacles; it involved the creation and strengthening of bonds and interpersonal relationships and considered the needs of the individual and his family and his surroundings. In health, the link consists

Published by Sciedu Press of the construction of relationships of affection and trust between professional and patient, allowing the deepening of the process of co-responsibility and continuous and longitudinal care. ${ }^{[14]}$

In the same scope, interpersonal relationships involve the interaction of two or more people who communicate, transfer values and energy from their roles in society (Borges et al., 2018). In HF, these concepts positively influence treatment adherence, change in lifestyle, monitoring and recognition, and response to symptoms. ${ }^{[15]}$ Still, they promote support in the face of the occurrence of psychological disorders. ${ }^{[16]}$

Contrary to the concern (Fuersorge), care for occupation (Besorgen) is due to obligation, mediated only by technique; impersonality prevails, that is, there is no perception of the other as an extension of one's presence (Dasein). ${ }^{[6]}$ In this study, inauthentic care was shown to be inadequate between the number of people with HF who need follow-up and the number of professionals in a team; in the absence of some professional categories; the lack of communication between health care networks and the lack of educational materials to support the patient and their families.

The weaknesses identified in the speeches are relevant and can negatively impact the prognosis of the person with HF. In the meantime, it is imperative to choose strategies that promote health as a life-affirmation, and not only as a reestablishment of physiological parameters, ${ }^{[17]}$ because planning care entails the integration between human beings (individual and disease characteristics), co-presence (social support and family bonds) and care ${ }^{[8]}$ to promote health and quality of life. ${ }^{[18]}$

Thus, in the speeches, the proposal for the development and implementation of an educational and follow-up application represents, for professionals, the possibility of caring beyond the hospital environment; it is to provide care to those who live far from the health institution, strengthen bonds and overcome social and access barriers to health. The meanings also included the programming of broad and updated educational content, to be used during the consultation; that sensitizes for the adoption of healthy behaviors, patient empowerment, encouragement for self-care, and a tool for monitoring health and social data.

The meanings found to refer to the professional's ways of existing. The being exists in its way (Selbst) and improper. Despite being to find oneself, most of the time, in his improper way, he can, by appropriating his existence, exercise his character, that is, be authentic, by questioning his way of existing and overcoming that that is established. The meanings related to the expectation of the application converged 
with the proper and inappropriate way of being-professional and this paradoxical complexity was due to coincidence (Selbigkeit), a way of acting together: expectations are for a technological tool that takes care, what is expected of the professional when being himself.

From the perspective of being-professional, care intermediated by an application must consider the clinical heterogeneity of the disease and the person; is to perceive management strategies and actions that value the individual and his uniqueness. Thus, the plurality of listed resources is justified. The incorporation of functionalities and resources in the application allows to reinvent care, creatively and, several times, playful, with positive reinforcements. ${ }^{[19-21]}$

That said, applications that provide resources that offer comfortable use to the patient, with interactive elements that provide reliable and personalized information, ${ }^{[22]}$ are not restricted to curiosity, since this represents the insatiable voracity for novelties, which reinforces the depersonalization and mischaracterization of the autonomy and respect for what is proper. ${ }^{[6]}$ Thus, it is not enough just to produce the new, but also to make it suitable for use.

The development of the application must take into account its purpose, the profiles of the users, identification of possible obstacles to its implementation, and ways of presentation and delivery to the end-user. It is from the being-to (Um-zu) of the application that we find the why (destination, Wozu) and, then, the being can take care of it. This discovery is made when there is the visualization of the work in its manuality (circumvention, Umsicht), giving the direction for the discovery of its being-to.[6] Thus, curiosity (Neugier) is overcome, and the user's relationship with technology becomes more original.

As for the main obstacles to using the application, the professionals showed concern for elderly patients, cognitive deficit, the sophistication of technology, accessibility, economic situation, digital literacy, and internet access. HF is a syndrome that mainly affects the elderly and causes important cognitive changes. ${ }^{[23]}$ In this context, the choice of resources such as increased font size and font, audio, and intuitive interface, can reduce these barriers and make the APP more suitable for use.
Regarding social barriers, despite socioeconomic differences, the cell phone is used by more than $67 \%$ of the population, which represents about two-thirds of the world, with more than 5.2 billion people. As a result, there is a growing interest in applications that facilitate daily activities and health, as smartphones have constantly evolved with the help of technological innovations. ${ }^{[24]}$ With this panorama, it is correct to say that the digital age permeates life and, in health, can contribute greatly to care.

Regarding the presentation and delivery of the application, during consultations, the professional team can influence the patient by clarifying and encouraging its use. The understanding of the dynamics of the adoption of this technology by the user is increasingly relevant and requires new mechanisms of awareness. ${ }^{[25,26]}$ In addition to the help of the team, the professionals highlighted the choice of social networks, as a means of dissemination and the possibility of greater reach. Still, they highlight the benefits of adaptation of the APP to other platforms that can facilitate their use.

Professionals were willing to implement an educational application and follow-up care for people who live with HF, as the perceived barriers were overcome by the announced benefits.

It is relevant to note that the research was based on the perception of the multidisciplinary team, which demonstrated high expectations regarding the application. Future research is still needed, including perspectives of all those involved in the care process, such as people with HF and their families and/or caregivers. Thus, it is possible to develop a technological tool for care.

\section{Conclusion}

The multidisciplinary team understands that people with HF demand singular and comprehensive care so that they can overcome the limitations of the disease. In this study, the professionals' expectations of an educational and follow-up APP were favorable to promote care and, thus, obtain better health results.

\section{Conflicts OF InTEREST Disclosure}

The authors declare that there is no conflict of interest.

\section{REFERENCES}

[1] Austin RC, Schoonhoven L, Richardson A, et al. How to SYMPtoms and management tasks in chronic heart failure imPACT a person's life (SYMPACT)? Protocol for a mixed-methods study? Esc Heart Fail. 2020; 7(6): 4472-7. PMid:32940966 https://doi.org/10
$.1002 /$ ehf 2.13010

[2] Boodoo C, Zhang Q, Ross HJ, et al. Evaluation of a heart failure telemonitoring program through a microsimulation model: cost-utility analysis. JMIR. 2020; 22(10). PMid:33021485 https : //doi .org/ 10. $2196 / 18917$ 
[3] Paula TR, Menezes AP, Guedes NG, et al. Effectiveness of mobile applications for behavioral changes in health: a systematic review. Rev Rene. 2020; 21: e43845. https://doi.org/10.15253/217 5-6783.20202143845

[4] Pezel T, Berthelot E, Gauthier J, et al. Epidemiological characteristics and therapeutic management of patients with chronic heart failure who use smartphones: potential impact of a dedicated smartphone application (report from the OFICS el study). Arch Cardiol Dis. 2021; 114(1): 1-8. PMid:32868257 https://doi.org/10.1016/j.ac vd.2020.05.006

[5] Son UJ, Oh S, Kim EY. Patient's needs and perspectives for using mobile phone interventions to improve heart failure self-care: a qualitative study. J Adv Nurs. 2020; 1(11). PMid:32672374 https://doi.org/10.1111/jan.14455

[6] Heidegger M. Ser e tempo. Rio de Janeiro: Editora Vozes; 2012.

[7] Guerrero-Castañeda RF, Menezes TMP, Prado ML. Phenomenology in nursing research: reflection based on Heidegger's hermeneutics. Esc Anna Nery. 2018; 23(4): 2e20190059. https ://doi.org/10 .1590/2177-9465-ean-2019-0059

[8] Cestari VRF, Moreira TMM, Pessoa VLMP, et al. The essence of care in health vulnerability: a Heideggerian construction. Rev Bras Enferm. 2017; 70(5): 1112-6. PMid:28977242 https://doi.org/ 10.1590/0034-7167-2016-0570

[9] Allida S, Du H, Xu X, et al. Health education interventions in heart failure. Cochrane DatabSyst Reviews. 2020; 7(7): 1-83. https: //doi.org/10.1002/14651858.CD011845

[10] DeVore AD, Granger BB, Fonarow GC, et al. Care optimization through patient and hospital engagement clinical trial for heart failure: rationale and design of connect-HF. Am Heart J. 2020; 22: 41-50. PMid:31770656 https://doi.org/10.1016/j.ahj . 20 19.09.012

[11] Athilingam P, Jenkins B, Redding BA. Reading level and suitability of congestive heart failure (CHF) education in a mobile app (CHF Info App): descriptive design study. JMIR Aging. 2019; 2(1): e12134. PMid:31518265 https://doi.org/10.2196/12134

[12] Lincoln YS, Guba EG. Naturalistic inquiry. Sage Publications; 1985.

[13] Teskereci G, Boz I. "I try to act like a nurse": a phenomenological qualitative study. Nurs Educ Pract. 2019; 37: 39-44. PMid:31071546 https://doi.org/10.1016/j.nepr.2019.03.009

[14] DeVore AD, Granger BB, Fonarow GC, et al. Care optimization through patient and hospital engagement clinical trial for heart failure: rationale and design of connect-HF. Am Heart J. 2020; 22: 41-50. PMid:31770656 https://doi.org/10.1016/j.ahj.20 19.09 .012

[15] Bugajski A, Buck H, Zeffiro V, et al. The influence of dyadic congruence and satisfaction with dyadic type on patient self-care in heartfailure. Eur J Cardiovasc Nurs. 2012; 20(3): 268-275. PMid:33611366 https://doi.org/10.1177/1474515120960002
[16] Lu F, Pu WT. The architecture and function of cardiac dyads. Biophys Rev. 2020; 12: 1007-7. PMid:32661902 https ://doi .org/10.1 007/s12551-020-00729-x

[17] Kyriakou M, Middleton N, Ktisti S, et al. Supportive care interventions to promote health-related quality of life in patients livin with heart failure: a systematic review and meta-analysis. Heart Lung Circ. 2020; 29(11): 1633-47. PMid:32723688 https://doi.org/10.1 016/j.hlc.2020.04.019

[18] Roy B, Wolf JRLM, Carlson MD, et al. An international comparison of factor saffecting quality of life among patients with congestive heart failure: a cross-sectional study. PLoSOne. 2020; 15(4): e0231346. PMid:32267902 https://doi.org/10.1371/journa 1.pone. 0231346

[19] Arulnathan A, Vaaheesan S, Denecke K. A mobile application for self-monitoring for patients with heart failure. Stud Health Technol Inform. 2019; 259: 113-6. https : //doi .org/10.3233/978-1-6 1499-961-4-113

[20] Windmon A, Minakshi M, Bharti P, et al. Tussis Watch: a smartphone system to identify cough episodes as early symptoms of chronic obstructive' pulmonary disease and congestive heart failure. IEEE J Biomed Health Inform. 2019; 23(4): 1566-73. PMid:30273159 https://doi.org/10.1109/JBHI . 2018.2872038

[21] Woods LS, Duff J, Roehrer E, et al. Patients' experiences of using a consumerm Health app for self-management of heart failure: mixedmethodsstudy. JMIR Hum Fact. 2019; 6(2): e13009. PMid:31045504 https://doi.org/10.2196/13009

[22] Wonggom P, Nolan P, Clark RA, et al. Effective ness of an avatar educational application for improving heart failure patients' knowledgeand self-carebehaviors: a pragmatic randomized controlled trial J Adv Nurs. 2020; 76(9). PMid:32395836 https : //doi .org/10 $.1111 / j$ an. 14414

[23] Vasan RS, Zuo Y, Kalesan B. Divergent temporal trends in morbity and mortality related to heart failure and atrial fibrillation: age, sex, race and geographic differences in the United States, 1991-2015. J Am Heart Assoc. 2019; 8: e010756. https ://doi.org/10.1161/ JAHA . 118.010756

[24] Gama LN, Tavares CMM. Development and evaluation of mobile application for the prevention of musculoskeletal risks in nursing work. Texto Contexto Enferm. 2019; 28: 20180214. https : //doi.org/10.1590/1980-265x-tce-2018-0214

[25] Han C, Witthaut D, Timme M, et al. The winner takes it all - competitiveness of single nodes in globalized supply networks. PLoS One. 2019; 14(11). PMid:31747436 https://doi.org/10.1371/jour nal. pone. 0225346

[26] Bilal M, Oxentenko AS. The impact of twitter: why should you get involved, and tips and tricks to get started. Am J gastroenterol. 2020; 115(10): 1549-52. PMid:327400 https://doi .org/10.14309/a jg. 0000000000000763 